\title{
Juan Luis Vives, lengua y lenguaje en el humanismo renacentista
}

\section{Juan Luis Vives, the Language and its Use in the Renaissance Humanism}

\author{
Juan Luis MonReAL PéreZ \\ Universidad de Murcia \\ jlmonreal@um.es
}

Recibido: $15-10-2010$

Aceptado: $15-12-2010$

\section{Resumen}

El objeto de este artículo es doble. Por una parte, examina el uso que Vives hace de la lengua y del lenguaje, y, por otra parte, indica sus aportaciones al campo de la traducción e interpretación. La diversidad temática presente en su obra hace que su persona sea un punto de referencia para diferentes campos científicos, entre ellos la Filología. Para Vives, tanto el acercamiento filológico, como el aprendizaje de la lengua no sólo deben tener en cuenta la lengua desde un punto teórico, sino también sociocultural. Su especial interés por las lenguas le llevó a realizar un considerable esfuerzo filológico haciendo lecturas e introducciones de varios textos clásicos latinos y también griegos, y transmitiendo su opinión acerca de la forma de realizar versiones o interpretaciones.

Palabras clave: Humanismo renacentista, aprendizaje de la lengua, filología, traducción.

\section{Abstract}

The aim of this article is to analyze the use of the language carried out by Juan Luis Vives. Due to the wide range of topics Vives dealt with, he has had a strong 
influence on different specialities like the philology. For Vives, the philological approach and the teaching of languages don't only have to take into account the language from a theoretical point of view, but also from a socio-cultural perspective. His great interest in languages moved him to pay attention on trying to find the real meaning of the original works in Latin and also in Greek. It also moved him to write introductory essays to them. By writing introductions and doing his interpretations, he communicated his own opinion about how to translate them.

Keywords: Renaissance Humanism, learning of the language, philology, translation.

\section{Introducción}

Este artículo tiene como objetivo examinar las contribuciones más relevantes de la obra de Juan Luis Vives a la lengua, a su uso y aprendizaje, así como al campo de la traducción e interpretación.

La metodología que se utiliza para la construcción del texto se soporta principalmente sobre fragmentos de obras de Vives que consideramos relevantes por sus contribuciones al objetivo fijado. Con carácter complementario también se recurre a textos de obras de otros autores que, a nuestro entender, ayudan a contextualizar, examinar y ver el alcance de la obra de Vives. Ello explica la abundancia y, al mismo tiempo, la necesidad de referencias que incorpora el texto, ya que éstas marcan su hilo discursivo, bien abriendo vías de reflexión, o, bien reforzando las propuestas de ideas que realizamos. En el análisis de los fragmentos de texto que se hace, ha sido considerado tanto lo que dice el texto, fondo o contenido, así como la forma del mismo (Cf. Krippendorff:1997 y Marcos:1990).

\section{Desarrollo lingüístico en el Humanismo renacentista español}

En primer lugar, algo que caracteriza el desarrollo lingüístico en el Humanismo renacentista español, del que Juan Luis Vives es "another major Renaissance thinker" (Cf. Waswo, 1980:525)1, es el uso simultáneo del latín y de nuestra lengua romance, como dos sistemas lingüísticos. Hay aquí una diferencia con respecto a Italia en lo que a Humanismo se refiere. Mientras que, por un lado, para los humanistas italianos, el Humanismo supone desde un principio un análisis cualitativo del uso del lenguaje, un uso que mejore el latín empobrecido en la Edad Media y recu-

\footnotetext{
${ }^{1}$ Cf. asimismo de este especialista en Vives su obra Language and meaning in the Renaissance, por
} el interés que tiene en relación a la problemática que aborda este artículo (1987:113-133). 
pere el latín modélico de la Antigüedad, en España -por el contrario-, el uso del lenguaje se asocia a la naturaleza de los contenidos.

Dentro del problema de la lengua en esta época conviene señalar dos aspectos: la oposición latín medieval frente a latín humanístico y la convivencia entre lengua latina y lengua romance, situación ésta última muy relacionada con el bilingüismo español que hace que un mismo hablante elige tratar ciertos temas, por ejemplo, académicos, en latín, mientras que para comunicarse en el ámbito familiar, preferirá utilizar la lengua romance.

De hecho, en España, en una primera época, aunque el uso del romance sea frecuente en el campo de la administración civil, de la predicación, o incluso de la ciencia, no obstante éste no se independiza totalmente del latín. Ello explica que quienes escriben en la lengua vernácula han llegado a ser cultos por su conocimiento del latín; por esta razón es muy importante que las fuentes latinas estén en un lenguaje claro que permita la transferencia de contenidos culturales de modo que pueda tenerse acceso a las mismas, tal y como era fomentado por el ideal humanístico de lengua. En cambio, el uso especulativo del lenguaje no contribuía de modo alguno a esa transferencia y divulgación.

En segundo lugar, el papel que desempeña la lengua está determinado por la evolución de los saberes y de la mentalidad, a lo que tanto contribuyó el Humanismo. Por esta razón, el empleo de la lengua latina y el valor literario y científico de las lenguas vulgares no son contrarios el uno del otro sino que contribuyen a la cuestión de cómo debe usarse la lengua del modo más efectivo posible:

¿Quién entre los antiguos hubiese podido alcanzar un lugar preeminente en la ciencia y la filosofía, sin ser capaz de expresar su pensamiento en un lenguaje cuidado? (Carrera, 1988:11).

La evolución de los saberes y de la mentalidad y su efecto en el desarrollo y uso de la lengua se produce gracias a los nuevos contextos históricos y culturales que conlleva el fenómeno del Humanismo renacentista español; entendemos por nuevos contextos históricos y culturales las nuevas condiciones que presentan los diversos factores que configuran el orden cultural y social de la época, bien expresados en lo político, lo social, lo religioso, lo lingüístico, etc. Entre todos estos factores, hay que resaltar el influjo decisivo que tuvo el rey Carlos y su idea y proyecto de Imperio en el desarrollo y uso de la lengua.

En tercer lugar, la tradición europea-erasmista del Humanismo renacentista español, basada en la combinación de los Studia humanitatis junto a la Philosophia Christi, va a propagar, por una parte el Humanismo y la Biblia, pero por otra, hará que se difundan los textos sagrados en las lenguas vernáculas del momento. En el caso de España, no hay más que ver la gran producción de literatura religiosa que tiene lugar en la lengua vernácula del Imperio, para observar la importancia que 
tuvo en el desarrollo de la lengua la cohabitación de los Studia humanitatis junto a la Philosophia Christi. No es pues casual que la primera institución que en España propulsó los Studia humanitatis, fuera la Universidad de Alcalá y que estuviera destinada al estudio integro de la doctrina cristiana, como queda bien patente en el gran peso que en dicha Universidad tuvieron los estudios de Teología y Sagrada Escritura.

En cuarto lugar, los humanistas renacentistas españoles supieron armonizar bien la necesidad del conocimiento de las lenguas clásicas, especialmente el latín, con el uso del romance, al que tanto contribuyeron en su desarrollo. La propia aportación de Luis Vives lo pone bien de manifiesto: aunque su producción científica la escribiera en latín, siguiendo el ejemplo de Erasmo y Lebrija, no obstante, Vives se convirtió en un gran defensor del uso y conocimiento también de las lenguas vernáculas, tal como se verá a continuación. El siguiente fragmento nos confirma la posición del valenciano en el modelo lingüístico que practicó:

La concepción lingüística de Vives es resuelta, como vemos, a favor del empleo del latín como lengua de expresión literaria y oral, en pacífica convivencia con las lenguas modernas, reconocidas como propias de cada hombre y, en consecuencia, respetadas como manifestación humana a la que es posible recurrir en caso de necesidad (Carrera, 1988:97).

Por último, queremos recordar el papel fundamental que la traducción tuvo en el periodo del Humanismo renacentista español para que se produjera, por un lado, la confluencia de dos sistemas lingüísticos, el latino y el romance y, por otro, se alimentara el desarrollo de las lenguas vernáculas con la intensidad que de hecho tuvo lugar.

El transvase interlingüístico se materializa en la traducción de una lengua a otra, ya que es un poderoso instrumento para la difusión de las ideas. La labor de traducción toma cuerpo, precisamente, para que el conjunto del pueblo tenga acceso a la lectura de obras doctrinales que son clave y de toda obra digna de ser divulgada, razón por la que esta actividad tiene gran importancia en la España de esta época y bien llevada a cabo por los humanistas renacentistas españoles.

\section{Las aportaciones de Juan Luis Vives a la lengua y al lenguaje}

En este epígrafe se estudian las contribuciones más significativas de Vives al campo de la lengua y lenguaje en general, especificándose al interior del mismo aquellos elementos que tienen más interés.

Pero antes de desarrollar dichos elementos, conviene recordar qué entiende el valenciano por lengua y lenguaje. La lengua la define al señalar lo siguiente: "la pri- 
mera capacidad que se desarrolla en el hombre es la de hablar, que al punto fluye de la razón y de la mente cual de un manantial [...] Y así como la mente la tenemos por don de Dios, así también la capacidad de hablar es algo natural en nosotros, pero que hablemos esta lengua o aquélla es cosa de arte y no de naturaleza" (Vives, 1997:75-Tomo II).

Lengua y lenguaje son dos conceptos que en Vives adquieren verdadera fuerza cuando son vistos desde la perspectiva de su obra filosófica. Al respecto escribe Valerio del Nero que "reconocer el relieve que tiene el lenguaje en la reflexión filosófica de Vives significa no sólo encontrar una clave interpretativa coherente de ese texto orgánico, sino también identificar la especificidad de la elaboración conceptual del español" (Nero: 1991:6). Por otra parte, Vives, con su forma de entender lengua y lenguaje, supera la concepción existente hasta ese momento del lenguaje que se reducía a describir la estructura de su lógica interna, sin establecer relación alguna entre lengua y sociedad, cosa que sí hace Vives al definir el lenguaje como el instrumento de la sociedad humana, tal como expone el siguiente fragmento:

El lenguaje constituye para Juan Luis Vives un elemento decisivo tanto para la socialización del individuo a través de la educación como para la propia configuración de la sociedad humana. El núcleo de su tratamiento del lenguaje está constituido por la articulación efectiva de las dos dimensiones que confluyen en el lenguaje en cuanto capacidad expresiva social del hombre (Nubiola, 1993:159).

Por todo ello, en opinión de Hidalgo-Serna, la filosofía del lenguaje de Vives merece ser valorada como una de las aportaciones más originales de su obra al pensamiento del siglo XVI. Esta valoración le lleva a decir:

No es casual que el De ratione dicendi apareciera un año después del De disciplinis (1531), el más extenso de sus tratados. Ambas obras encierran la clave común de su humanismo filosófico y de su singular concepción del lenguaje (Hidalgo-Serna, 1998:X) $)^{2}$.

El hecho de examinar las contribuciones específicas de Vives a la lengua y al lenguaje no debe impedir, sin embargo, tener una visión general de la obra de Vives que incluya aquellos aspectos más relevantes de la misma y que permitan romper con la visión fragmentaria y, a veces reduccionista, que del valenciano se tiene frecuentemente debido al modo de abordar su figura por los tratadistas del mismo a lo

\footnotetext{
2 Cf. otros trabajos del autor al respecto como Metaphorical language, Rhetoric, and Comprehensio: J.L. Vives and M. Nizolio (1990); Ingenium and Rethoric in the work of Vives (1983); Vives, Calderón y Vico. Lenguaje metafórico y filosofar ingenioso (1992).
} 
largo del tiempo. A veces, se nos ha transmitido el Vives filósofo, teólogo, político, moralista, filólogo-lingüista, psicólogo, jurista, pedagogo, etc., como Vives diferentes:

[...] Vives has been better known to posterity as a polemicist, pedagogue, and scholar than as philosopher per se. His reputation as the "father of modern psychology" and the chief precursor of Francis Bacon dates from around the turn of this century and continues with some qualifications, to prevail today. In his own time, his widest fame was secured by his straightforwardly popular and didactic tracts on wisdom and the duties of Christian marriage (Waswo, 1980:596).

Sin embargo, el único Vives que hay está caracterizado por su gran interés por el conocimiento y por su transmisión, hecho que explica su contribución científica al desarrollo de los diferentes campos disciplinares.

Precisamente por esto hay que indicar, como un primer aspecto general en la obra de Vives, su aportación al saber científico. La insatisfacción que le produjo ver el estado del saber en general en su tiempo y, concretamente, la orientación dialéctica de la filosofía le llevó - guiado por su espíritu positivo-, a ofrecer su propia contribución a la forma de entender el saber y la lengua, distanciándose de esta manera del modo tan artificial como los dialécticos lo entendían:

¿Quien hay que no vea que la dialéctica es la ciencia del lenguaje? Eso lo dice el mismo vocablo griego. ¿De qué lenguaje es esa vuestra dialéctica? ¿Del francés o del español? ¿Del godo o del vándalo? Del latino, a buen seguro no lo es. El dialéctico debe usar de aquellas palabras y de aquellos enunciados que sean entendidos por todo el que conozca la lengua que habla, latina si es en latín en que el dialéctico dice expresarse: griega, si en griego. Y con todo, esos que a su decir hablan latín, no son entendidos ni por los más duchos en esa lengua, ni aun a veces por quienes son de la misma harina o, mejor, del mismo salvado (Vives, 1948:295- Tomo II) ${ }^{3}$.

Vives le asigna al saber científico una base humana/antropológica, razón por la que el hombre se constituye en el centro del desarrollo de la ciencia, contradiciendo de esta forma toda especulación y artificialidad que corría por el saber oficial y por el uso del lenguaje en los centros universitarios, alejados de los verdaderos problemas que realmente preocupaban e interesaban al hombre. Desde esta perspecti-

\footnotetext{
3 La cita de la obra de Vives Contra los Seudodialécticos está tomada de la traducción de Lorenzo Riber de las Obras Completas de Juan Luis Vives, al no disponer de otra traducción española que permita entender su pensamiento en la totalidad, ya que en opinión de Francisco Calero la obra de Vives a través de la traducción de Lorenzo Riber solo se puede entender al 80\% (Cf. Calero 1998:533 y 1996:245). La opinión de Calero es también compartida por otros especialistas en Vives (Cf. Jiménez: 1978: 98). En lengua inglesa puede consultarse la edición crítica de Ch. Fantazzi de la obra de Vives In Pseudodialecticos (1979).
} 
va, Vives considera que las diferentes disciplinas que conforman el saber científico como el lenguaje, deben articularse en torno a lo humano:

Esta polarización hacia el hombre constituye un rasgo muy definidor en la concepción vivista del saber. Tanto en la misión y sentido general del mismo, como en el enfoque concreto de sus ramas [...] Las artes han de buscar, en conjunto, el perfeccionamiento y desarrollo humano. De aquí la valoración de la medicina y la filosofía moral, el estudio de la organización social. Así en el caso de la lógica [...] El denominador común de este enfoque es, como decíamos, el asentamiento de la investigación lógica sobre la naturaleza humana, en sus grandes manifestaciones del lenguaje y la conducta, o los procesos síquicos en general.

Indudablemente que allí donde esta vocación integradora de la ciencia en el hombre nos aparece con máxima claridad es en el Vives sicólogo, pedagogo, pensador social y jurídico. Es en ciencias en que por su propia índole pisamos el suelo de lo humano, donde Vives ha alcanzado sus intuiciones y aportaciones más geniales, de sobra reconocidas (Paris, 1962:254,257).

Otro aspecto relevante en la obra de Vives y que también conviene mencionar es su condición de humanista (Cf. Waswo, 1980:595; Fontán, 2008:169, 175) que aparece en cada uno de los temas que aborda. Al ser el Humanismo una forma de pensar general, una nueva cultura que asume el hombre en relación al mundo, lógicamente esto se refleja en todos y cada uno de los campos que se constituyen en su centro de interés (Cf.Ortega y Gasset, 1961:63).

La actitud humanista de Vives está presente en el conjunto de temas que el valenciano aborda en su obra. Pero la mirada que proyecta sobre cada uno de los problemas que analiza, no es pura especulación ni distanciamiento; más bien es cercanía y compromiso con ellos. Éste fue el comportamiento real que Vives adoptó a lo largo de su vida, pero especialmente en su etapa madura y final, cuando la experiencia de lo visto y vivido le orientaron a un humanismo pragmático. Por esta razón, no escribe reglas gramaticales abstractas sino buscando su aplicación práctica:

Tanto era así que Moro rechazaba el fundamento mismo de un sentido limitado del humanismo: Vives no parecía escribir mirando los viejos libros, sino que más daba la impresión de partir de la observación directa de los sentimientos. No apreciaba Tomás Moro una mera relación abstracta, alegórica o simbólica con el tiempo presente, ni una significatividad originada en la mera asociación de ideas. Con sus afirmaciones, Moro rompía la imagen del humanista como un hombre apartado, pedante y preocupado por la corrección gramatical, y nos descubría un Vives que hablaba de sí mismo y contaba una historia, con tal implicación, que parecía «la que le ha tocado vivir personalmente a él y sus exhortaciones no proceden de un sujeto ajeno en forma lánguida, sino que vienen impulsadas con gran viveza de sus propios sentimientos de temor, esperanza, riesgo y prosperidad» (Villacañas, 2008:110). 
La consideración tan extendida de Vives como un gran humanista y, además, practicante de un humanismo pragmático, nada teórico y desentendido de la realidad, sino que comprometido con el tiempo y los problemas que le toca vivir, tiene que ver con su formación y sensibilidad filosóficas. Desde la filosofía, Vives ha aprendido el valor y la centralidad del hombre; desde la filosofía, Vives ha descubierto la importancia de la metafísica y la antropología como disciplinas que reflexionan sobre el ser del hombre (Cf. Gómez-Hortigüela, 1993:85). Desde esta formación filosófica e impregnado por la nueva cultura renacentista (Cf. Durán, 2000:179), Vives tiene la base necesaria para la defensa y práctica de la filosofía humanística, razón por la que resulta indiscutible el calificativo que se le da de ser uno de los más grandes filósofos humanistas, si no el más grande de su tiempo:

Debemos recordar, ante todo, que para los autores del siglo XVII y XVIII, como Naudé o Mayans, Vives fue un escritor político. Esta vieja intuición es acertada, por mucho que hoy nos parezca reducir la grandeza de Vives, quien a nosotros, como ya a Erasmo, nos parece «muy versado en todas las ramas de la filosofía» (Villacañas, 2008:81-82).

Visto el contexto general de la obra de Vives, a continuación analizamos su contribución al campo de la filología y del lenguaje, puesto que este territorio constituye la perspectiva específica o la mirada que especialmente interesa, teniendo en cuenta el carácter del artículo. A tal fin, consideramos su pensamiento en torno a algunos aspectos relacionados con este campo, como son la lengua, el lenguaje, el arte de hablar y el modo de entender la traducción. De entre la abundante producción literaria de Vives, existen los suficientes materiales que nos permiten identificar y reconocer su pensamiento para cada uno de los aspectos mencionados.

\subsection{Uso y estudio de las lenguas}

Juan Luis Vives se desarrolla en los primeros años de su vida en un clima lingüístico plural. El castellano y el valenciano forman su bagaje lingüístico natural, aparte de su temprano aprendizaje del latín. El destino que le esperaba, Francia, Países Bajos e Inglaterra le permitiría incorporar también de forma bastante natural el francés, flamenco e inglés, además del buen dominio del latín y buen conocimiento del griego. Por tanto, estamos ante un humanista que practicó con su ejemplo el uso de las lenguas, clásicas y vernáculas, entendiéndolas como instrumento lingüístico y forma de comunicación cultural. En cuanto a este aspecto, Vives adoptará una posición más abierta y funcional que Erasmo. Aunque ambos valoran el latín como la lengua por excelencia haciendo un uso exclusivo de la misma en sus escritos, sin embargo la referencia a las lenguas vernáculas en Vives es mucho mayor que en Erasmo. Posiblemente, la diferencia de edad entre uno y otro, veinti- 
cinco años mayor Erasmo que Vives, explique tal situación, ya que en este cuarto de siglo muchas cosas cambiaron, entre otras, la implantación de las lenguas vernáculas iba extendiéndose y consolidándose.

Vives no solo será un usuario de las lenguas, sino que se ocupa de las mismas en sus escritos, reflexionando acerca de la lengua en general y proponiendo metodologías para su aprendizaje. Son varios los escritos de Vives en los que se ocupa de estas cuestiones: De ratione studii puerilis (1521), dos cartas que versan sobre la enseñanza de las lenguas; De tradendis disciplinis (1531) ${ }^{4}$, ambicioso tratado de la enseñanza de todas las disciplinas; De ratione dicendi (1533) o retórica, en donde se dedican capítulos a la manera de expresarse, la dialectología y la teoría de la traducción; De conscribendis epistolis (1536), dedicado al arte de escribir cartas y que es un libro introductorio sobre fórmulas, formatos, contenidos y tipos de cartas al nivel del principiante avanzado o estudiante intermedio; Linguae Latinae exercitatio o Los Diálogos (1539), que constituyen un buen material para la conversación y en los que se encuentran expresiones coloquiales latinas. Es un libro de frases, de lectura, de conversación y de práctica de formas y estructuras (Cf. BrevaClaramonte, 1994:49-50).

En las muchas y variadas reflexiones que Vives hace en su escritos a propósito de las lenguas y de la lengua, el valenciano plantea una cuestión de carácter general que consideramos de gran utilidad e, incluso, de actualidad: el conocimiento de las lenguas es algo que no se agota en sí mismo, sino que son un medio que nos sitúan a las puertas de las artes, de las disciplinas y de los saberes. La necesidad de las mismas hay que entenderla, según Vives, desde esta perspectiva, tal como lo expresa en su obra De Disciplinis, en la Parte Segunda (Tomo II), dedicado a La Enseñanza de las Disciplinas o la Formación Cristiana:

Hasta este punto nos hemos ocupado del conocimiento de las lenguas que posibilitan el acceso a todas las disciplinas y a todas las artes, muy especialmente a aquellas que nos han sido transmitidas en las obras literarias de los grandes talentos. Por consiguiente, el desconocimiento de una determinada lengua cierra, por decirlo de algún modo, la puerta de entrada a la disciplina que está escrita y redactada en esa lengua. Pero recuerden los hombres aplicados al estudio que, si no añaden nada al conocimiento de esas lenguas, tan sólo han llegado a los umbrales de las artes y se hallan enfrente de ellas o, para ser más exactos, en el vestíbulo; y recuerden igualmente que no es mejor conocer el latín y el griego que el francés y el español, toda vez que los eruditos se han visto privados de sacar provecho de su uso, ni que todas las lenguas del mundo merecen que uno se sacrifique exclusivamente por ellas en el supuesto de que no se busque una finalidad distinta (Vives, 1997: 149-Tomo II).

\footnotetext{
4 Este escrito es la segunda parte de la gran obra de Vives De Disciplinis (1531), siendo la primera, De causis corruptarum artium y la tercera, De artibus. De tradendis disciplinis, la segunda parte, por su contenido y la filosofía que lo orienta puede servir de modelo de texto humanístico (Cf: Nero, 2008).
} 


\section{1) El uso del latín}

Conviene recordar de nuevo que Vives, al igual que lo hizo Erasmo, escribió toda su amplia obra en latín, y además en el latín del humanismo. Esta situación le vino impuesta, ya que el latín -pese a que las lenguas vernáculas en este tiempo empiezan a ganar terreno-, era la lengua oficial en las universidades ${ }^{5}$ y en toda la producción científica que se generaba en ellas o en su entorno. Con el aprendizaje que Vives adquirió de esta lengua en su formación inicial de Valencia, su ciudad natal, y el perfeccionamiento que consiguió en su segundo período parisino de formación, logra hablar y escribir un latín perfecto:

Hay un hecho, sin embargo, que no ofrece duda. Cuando a sus diecisiete años el joven Vives llega a París para cursar Artes, es decir, filosofía, dominaba el latín, había estudiado griego y poseía una respetable erudición histórica, cultural y literaria en relación a la antigüedad grecorromana. Sería imposible que sin una base de cierta consistencia hubiera podido acumular los saberes latinos y literarios que muestran sus primeras publicaciones parisinas, habiéndose dedicado además a otras materias y lecturas, e incluso a enseñar él mismo (Fontán, 1992:27).

El conocimiento teórico y práctico que Vives tiene de la lengua latina no obedece ni a la casualidad ni a la pura funcionalidad y utilidad. Hay un plus adicional que le lleva a hablar y escribir en latín como una segunda lengua materna: el espíritu del humanismo.

La elección del latín como vehículo de expresión literaria le vino impuesta a Juan Luis Vives por los usos contemporáneos. Pocos entre los humanistas de su tiempo concebían otra cosa. Auque las lenguas vulgares florecieran ya en la poesía, en la novela, en el teatro, en los libros de devoción y de historia, era impensable su empleo en la filosofía. Y para Vives, como para los demás humanistas de su tiempo, filosofía era todo lo demás (Fontán, 1977:42).

Para todo humanista, y más de la talla de Vives, el conocimiento profundo del latín, el disponer de fuentes latinas desprovistas de falsas adherencias, es el mejor

\footnotetext{
$5 \mathrm{Al}$ respecto tiene interés el siguiente comentario de Lorenzo Riber, en el que señala que pese a la oficialidad del latín en una universidad tan relevante en aquel tiempo como Lovaina, ello no impedía el uso cotidiano de las lenguas vernáculas: "iQué enorme zumbido el de las colmenas estudiantiles de Lovaina en los comienzos del siglo XVI! En los días de Vives, esa tétrica ciudad llegó a albergar más de siete a ocho mil estudiantes procedentes de todos los puntos de Europa. Una vez salidos de las aulas, donde imperaba el latín, sus calles resonaban con todos los acentos de una bulliciosa Babel plurilingüe" (Riber en Vives, 1947:40-Tomo I). Lo dicho para la Universidad de Lovaina es aplicable a las universidades hispanas, caso de Salamanca, pues ni siquiera en el Colegio Trilingüe se hablaba el latín de forma permanente (Cf. Moreno, 2006:163).
} 
camino para el desarrollo de las diferentes disciplinas, por una parte, y para el progreso de la sociedad moderna, por otra parte. Esta forma de pensar le hará a Vives vincularse tan fuertemente con toda la tradición clásica latina y, muy especialmente, con la obra de Cicerón, con Valla, con Nebrija y con Erasmo, entre otros. Por todo ello, el latín será para Vives la lengua en la que se expresa la cultura que respira y será su instrumento habitual para la escritura, la lectura y el pensamiento:

Hay en Vives una especial predilección por el lenguaje en la concepción unitaria de la cultura y aunque propone el idioma materno como elemento inicial en la escuela elemental, es el latín -sin embargo- no solo la lengua de cultura sino su primera lengua, pues en ella escribe, lee y piensa. De manera que latín y elocuencia formarán un binomio inseparable en las propugnaciones de la renovación de la cultura (Esteban, 1997:10).

La estancia de Vives en París, en efecto, le dio la oportunidad de familiarizarse con el mundo clásico, por un lado, y con la obra de Erasmo 6 , por otro; ambas direcciones, en definitiva, se complementaban. De esta forma, el valenciano compensaba así las decepciones que le causaba el estado de la filosofía que encontró en la universidad de París, excesivamente ocupada en la enseñanza de la dialéctica estéril utilizando, a veces, un latín que dejaba bastante que desear para un espíritu humanista como él.

París le ofreció a Vives la oportunidad de adentrarse en la antigüedad clásica, a partir de los conocimientos básicos adquiridos en su Valencia natal. La antigüedad clásica le producía atracción por la elocuencia que exhibía y la sabiduría que demostraba a través del lenguaje utilizado, expresado en latín y griego primordialmente. Por ello, el buen manejo del latín, en su caso, se constituye en el medio de acceder al conocimiento del mundo clásico, que le permitirá conseguir un discurso elocuente y una mente ilustrada. Independientemente de que para Vives el latín fuera su lengua clásica principal, tampoco descuidó el conocimiento del griego y la posibilidad de acceder a las fuentes originales escritas en esta lengua, demostrando a lo largo de sus escritos tener de dicha lengua un buen manejo.

\footnotetext{
${ }^{6}$ Se puede decir que toda la trayectoria intelectual de Vives está marcada por el Erasmismo como filosofía humanista. Su sensibilidad por esta corriente existe mucho antes de que Vives y Erasmo se encuentren posiblemente en Lovaina. Lógicamente, el encuentro vendrá a reforzar la trayectoria seguida, fruto de la amistad y colaboración que se generan a partir de este momento. Sin embargo, parece ser que la amistad que existe entre ambos se enfría partir de un determinado momento, al parecer debido a diferencias derivadas del modo distinto de relacionarse ambos con la teología y la filosofía (Cf. Calero:1996:241-243). Pero, especialmente influyó en tal enfriamiento, los comentarios vivesianos a La Ciudad de Dios, de san Agustín, dentro de los Opera Omnia de Erasmo y su edición de Froben de 1522, que resultó un fracaso de ventas y que Erasmo lo atribuyó a lo denso de los comentarios de Vives. Este enfriamiento no fue baladí, pues fue origen del boicot por parte de los impresores de Basilea al valenciano, hasta que murió Erasmo en 1536, pudiendo publicar allí luego.
} 
Fruto de la convicción y esfuerzo que Vives había depositado en el latín como instrumento imprescindible para un humanista como él, están los primeros escritos de su primera etapa como escritor. En ellos Vives utiliza un latín fluido, con bello estilo y con gran soltura. Todo el vasto trabajo que Vives llevó a cabo en su estancia parisina: lecturas abundantes, acceso a diversos documentos, conocimiento de autores clásicos, le obligó a familiarizarse con el latín como lengua también natural.

Pero en el empleo que Vives hace del latín como lengua principal, su uso no responde a seguir rígidamente los modelos clásicos o estilo ciceroniano, sino que construye el latín con mentalidad actual, es decir, humanista. Por ello, una de las grandes virtudes de Vives es que sus escritos se adaptan a la realidad del lector.

Con su escribir en latín, Vives mantiene, por una parte, la tradición clásica en cuanto orientación general, pero por otra parte, incorpora el espíritu humanista, es decir, utiliza los recursos lingüísticos del momento y hace referencia a los problemas del tiempo en el que vive; en esta forma de escribir está el atractivo que produce la lengua latina usada por el valenciano.

Posiblemente, el descubrimiento y el conocimiento de los escritos de Erasmo por parte de Vives, durante su etapa de formación parisina, fue un segundo factor que le influyó positivamente en el buen uso del latín: Erasmo, además de ser el líder natural europeo del Humanismo cristiano renacentista, situación compartida por Vives, también escribió toda su obra en latín, en cuya construcción no seguía de modo inflexible la tradición clásica, sino que lo elaboró con mentalidad actual y moderna, tanto lingüística como temáticamente hablando. Dos coincidencias, que lógicamente explican la influencia que Erasmo ejerce sobre Juan Luis Vives.

Los resultados de la actividad literaria de Vives, desde la perspectiva del uso del latín, puede caracterizarse por la abundancia, la calidad y la evolución lógica que a lo largo de su vida fue teniendo. Toda la progresión y mejora que se observa en el lenguaje que utiliza se explica por la exigencia que Vives se autoimpone desde su filosofía humanista:

En veinticinco años de actividad literaria el humanista valenciano Juan Luis Vives compuso en latín una vasta obra de varios miles de páginas, que comprende ensayos y diálogos de carácter literario, pedagógico y didáctico, prelecciones y anotaciones filológicas, escritos políticos -de carácter doctrinal unos y comentarios de actualidad otros-, trabajos de apologética, meditaciones religiosas y estudios e investigaciones de filosofía y psicología. A lo cual hay que agregar algo más de un centenar de cartas -también en latín, salvo dos conservadas en castellano, una de ellas fragmentaria-, que son, probablemente, el exiguo resto de la nutrida correspondencia que, igual que tantos selectos espíritus del siglo XVI, mantuvo con personalidades públicas, intelectuales y amigos a lo largo de su vida [...] Comparando unos con otros los libros de estas series se podría descubrir la evolución de la prosa vivesiana en léxico, composición y estilo, así como 
la proyección sobre los escritos de la experiencia vital y de la actitud del autor, al enfrentarse con temas semejantes en el fervor humanístico de sus tiempos mozos y desde las serenas orillas de la madurez (Fontán, 1992:71-72).

Aparte del convencimiento que tuvo Vives de la necesidad de escribir en latín, debido a su condición de humanista y hombre de estudio, habían también otras razones adicionales que le reforzaron en dicha convicción: la estabilidad como lengua que el latín ya tenía, después de su empleo secular; no ser en ese momento una lengua hablada vulgarmente, por lo que era necesario que se usara de modo que resultara familiar a todos los lectores; la existencia de una gramática consolidada, por lo que no era obligado centrarse en cuestiones que no fueran pragmáticas, y que permitía centrar todos los esfuerzos en combinar gramática y uso. Otra de las ventajas del latín era la amplia variedad de autores latinos que podían servir de referentes, con modelos también diversos de estilos, pero sin imitar servilmente a ninguno de ellos y primando a cualquiera de ellos según la finalidad de la que se trate. Declararse admirador de Cicerón, como eran Vives y Erasmo, quería decir imitarlo en lo imitable, pero no cuando se trataba de abordar cuestiones que habían cambiado con el paso del tiempo transcurrido (Cf. Núñez, 1993:46-53). Ambos consideraban que el latín era una lengua literaria creativa y no muerta, y por ello la usaron. Pero el empleo literario creativo que de ella hicieron, les llevó a escribir con sentido de la tradición clásica, pero también con flexibilidad y actualidad.

\section{2) El uso de las lenguas vernáculas}

La relación de Juan Luis Vives con las lenguas vernáculas, marca un claro avance respecto a lo que fue, por ejemplo, la posición de Erasmo

[...] A pesar de que Luis Vives consideraba el latín como la lengua perfecta para la comunicación entre los hombres de su tiempo, y a pesar de que en la lengua del Lacio escribió en torno a sesenta obras, unas muy breves y otras muy amplias, tuvo siempre, y esto a diferencia de su amigo Erasmo, un gran aprecio por las lenguas vulgares o, si se prefiere, las lenguas maternas (Calero, 2009).

Ya abundaba suficiente literatura vulgar en distintos géneros (poesía, novela, teatro, religiosa, historia, etc.) que, sin lugar a duda, este hecho no debía ser desconocido por Vives. Por otro lado, éste nace en un contexto de claro bilingüismo: el valenciano y el castellano eran sus dos lenguas naturales en los ámbitos familiar y social, hasta que marcha a estudiar a París. Lógicamente, esto no pudo dejar de influirle y de sensibilizarle con esta realidad lingüística. Por tanto, el Vives de la infancia y adolescencia es un Vives, lingüísticamente hablando, socializado con las 
lenguas vernáculas (Cf. Fontán, 1977:37-41). Durante la estancias de Vives en París, Flandes e Inglaterra, Vives mantendría estas lenguas vivas, tanto por el buen número de estudiantes y profesores españoles que residían en París, provenientes especialmente de Cataluña, Aragón y Valencia, como por la amplia colonia de comerciantes españoles que vivían y comercializaban en la pujante y próspera Flandes, así como por la familia que Vives formó en Brujas, precisamente con una hija de los Valldaura, familia de comerciantes de origen valenciano y en cuya casa se instaló a su llegada a Flandes; igualmente, el tiempo que pasó Vives en Inglaterra en estrecho contacto con Catalina de Aragón, esposa de Enrique VIII, seguro que le favoreció para mantener vivas sus dos lenguas maternales (Cf. González, 1992a:37-39).

Es fácil ver en el conjunto de la obra de Vives el reconocimiento que hace de la lengua vernácula, aunque siempre toma las cautelas necesarias para que prevalezca la hegemonía del latín y del griego sobre ésta:

[...] Y no hubo nadie que fuese un perfecto conocedor de la lengua latina a no ser que estuviese también imbuido de la griega, pues de la lengua griega manó la latina y de la latina la italiana, la española y la francesa, naciones éstas para las que otrora fue la lengua latina vernácula.

Sabemos por experiencia que la lengua latina se torna más fecunda y elocuente desde la griega. Asimismo, desde la latina, las restantes lenguas de Europa, pero sobre todo aquellas tres que acabo de mentar. Los hablantes de estas tres lenguas convendría que se acostumbrasen al latín, no sólo para que entendieran bien éste mismo y a través de él las artes todas, sino también para que desde aquél volvieran su lengua patria más pura y más rica, cual curso de agua que con caudal más profuso fuera derivado de la fuente (Vives, 1997:79-Tomo II).

Independientemente del uso exclusivo que Vives hizo del latín en sus escritos, valoró -no obstante también-, la importancia que tiene el aprendizaje de otras lenguas:

Si alguno, sin embargo, posee talento y memoria, tiene una edad adecuada y tiempo libre bastante, y está provisto de diligencia e interés, a éste nada le querría yo vedado. Al contrario, a alguien tan felizmente preparado mucho lo exhorto a acometer el trabajo de las lenguas y artes todas (Vives, 1997:80-Tomo II).

\section{2. La lengua en el universo de la obra de Vives}

Vives no se limita en sus escritos a recomendar la utilidad de las lenguas en general, del latín y griego en particular, y del uso de la lengua vernácula, la propia, como instrumento para el aprendizaje de las llamadas lenguas clásicas u originales. 
Juan Luis Vives va más allá. Detrás del uso y del conocimiento de las lenguas, éste define la funcionalidad de la lengua y del lenguaje ${ }^{7}$, por algunas características que para él explican el sentido y la utilidad de su uso.

\section{1) Dimensión personal y social de la lengua}

Vives considera ambos aspectos totalmente relacionados, ya que su ser y sentido radica en la propia condición humana, resultado de la dimensión individual y social que ésta tiene. A nivel personal, la lengua -en opinión de Vives-, es algo natural, no un puro artificio. Es algo que mana de la razón y de la mente:

La primera capacidad que se desarrolla en el hombre es la de hablar, que al punto fluye de la razón y de la mente cual de un manantial. Por esto, todas las bestias así como carecen de mente, así también están privadas de habla [...] Y así como la mente la tenemos por don de Dios, así también la capacidad de hablar es algo natural en nosotros, pero que hablemos esta lengua o aquella es cosa de arte y no de naturaleza (Vives, 1997:80Tomo II).

Pero el hecho de que la lengua sea algo natural al hombre, no quiere decir que esta facultad humana se desarrolle y crezca espontáneamente, sin necesidad de ser cultivada. Nada de esto, en opinión de Vives. Hay que ayudarla a que se desarrolle desde la más temprana edad. Y el hecho de que el habla no crezca por igual en todos, no contradice la existencia de este don, sino que confirma la diferente aportación personal y social en su progreso:

Por este motivo, los padres en el hogar y el maestro en la escuela han de poner empeño en que los niños hablen bien su lengua patria y sean elocuentes, en la medida en que su edad lo permita.

Para la consecución de este fin serán de gran ayuda los padres, si ellos mismos, aunque sólo sea por el bien de sus hijos, se esmeran en expresar los sentimientos de su espíritu en palabras castizas y frase íntegra y adecuada. Luego, si cuidan de que las nodrizas y los ayos y aquéllos entre quienes la infancia de sus hijos transcurre, obren de idéntica manera y no hablen con embrollo, desatino y tosquedad, ni posean vicios de pronunciación que con facilidad contrae la tierna edad. Por esta causa, quería Crisipo que se escogiesen también nodrizas doctas. Mucho importa, dice Cicerón, a quiénes escucha uno diariamente en casa, con quiénes habla desde su niñez, cómo se expresan los padres, preceptores y madres. Esto es esencial para que aprendamos bien las lenguas,

\footnotetext{
${ }^{7}$ Las ideas principales de Juan Luis Vives sobre su concepto de lengua y lenguaje están contenidas en sus escritos De tradendis disciplinis y De ratione dicendi. Ambos escritos pertenecen a lo que se ha denominado su etapa de madurez y de mayor creatividad (Cf. Rodríguez, 2000:LXXIII-LXXVIII).
} 
que nos procura el arte, y también para que de manera expedita comprendamos los pensamientos ajenos y expongamos los nuestros (Vives, 1997:75-76-Tomo II).

Por otra parte, a nivel social, Vives considera que el lenguaje es el instrumento de comunicación social. Los humanos necesitamos códigos lingüísticos para relacionarnos:

Es, además, el lenguaje el instrumento de la sociedad humana. Y es que no de otro modo podría manifestarse el alma oculta bajo tantas envolturas y tan gran espesor del cuerpo (Vives, 1997:75-Tomo II).

Vives al subrayar la dimensión social del lenguaje deja abierta la reflexión que más tarde se ha hecho en relación a esta dimensión fundamental para la comunicación humana. Ambos aspectos del lenguaje, el individual y el colectivo, que Vives puso de manifiesto en sus escritos han resultado relevantes para las modernas teorías que se han elaborado en torno a esta disciplina:

Si Demócrito llamó al habla, por tal motivo, “fluencia de la razón”, Vives, avanzado a su tiempo y adelantándose a nuestros teóricos actuales de la Comunicación y de la Semiología, la califica de "instrumento más apto" que existe para "recíproca comunicación". De este modo, Vives emplea el término habla en sentido saussureano, de realización individual de la lengua, y el de comunicación, en el sentido actual de la Semiología lingüística o de la teoría de la comunicación verbal: el intercambio de información pragmática entre personas en una determinada situación comunicativa (Mourelle de Lema, 1993:215).

\section{2) La lengua y su poder social}

Otro aspecto puesto de manifiesto por Vives en relación al lenguaje es el poder que éste ejerce en la sociedad, en el ámbito humano. En la obra De ratione dicendi (1533) [Del arte de hablar], Vives señala dos cuestiones en relación al mismo: la primera, es el valor social que tiene la palabra y la importancia del lenguaje para la sociedad, llegando a equipararlos con el valor que tiene la justicia para la sociedad:

Quienes dijeron que el vínculo de la sociedad humana era la justicia y el lenguaje captaron con extraordinaria agudeza la esencia de la naturaleza humana. De estos dos atributos, es ciertamente el lenguaje el que goza de mayor influencia y poder entre los hombres, porque la justicia, en tanto que apacible y blanda, sólo es sentida como obligación en las conciencias de quienes han sido educados en la rectitud y la honradez; el lenguaje, en cambio, no sólo ejerce su poder de seducción sobre las mentes, sino que también extiende su dominio sobre los afectos, cuya influencia sobre el hombre todo resulta 
despótica y un pesado lastre. [...] Ahora mi objetivo es tratar sobre el lenguaje, sobre lo mucho que influye en toda situación y circunstancia, y sobre las admirables obras de las que es autor. Y puesto que nadie deja de constatar día a día, no ya en los demás, sino en sí mismo, el poder que éste entraña, me sorprende que haya quienes den poca importancia a la disciplina que enseña el funcionamiento del lenguaje, disciplina que resulta extremadamente útil en asuntos de trascendencia, si se hace un correcto uso de ella, como en extremo dañina, si se hace uno incorrecto (Vives, 2000:3).

La segunda cuestión que Vives también indica es el poder que se ejerce sobre los demás con el dominio del lenguaje. No cabe duda que Vives, al hacer esta reflexión sobre la lengua, de nuevo se está adelantando a otro ámbito disciplinar, la Sociología del lenguaje que se desarrollará a partir de los pasados años 50 (Cf. Fishman:1979). La palabra ejerce un poderío entre los hombres, y aquél que la maneja mejor despliega influencia sobre el resto:

Por ello, el que mayor dominio tiene del lenguaje es el que mayor poder tiene en toda congregación y sociedad, y claramente reina entre los hombres el que más capacitado está para hablar. Con razón, el trágico Eurípides llamó reina a la elocuencia.

Por este motivo, allí donde la libertad lo propició y, por así decir, la alianza entre el derecho y las leyes encontró una especie de equilibrio, allí fue donde el lenguaje, como un instrumento de poder, alcanzó un mayor grado de desarrollo y perfección gracias a los numerosos estudios de que fue objeto (Vives, 2000:9).

\section{3) Materia y forma en la lengua}

En el análisis de la lengua que Vives hace, diferencia entre cuerpo y el alma como dos realidades lingüísticas complementarias. Señala claramente en sus escritos que la atracción del lenguaje se produce cuando las palabras, como objeto material (el cuerpo), están bien construidas y elocuentemente dichas. Pero éstas deben, a su vez, transmitir ideas, mensajes, como objeto formal (el alma). Las ideas son, pues, el espíritu de las palabras, las que le dan sentido. Uno y otro elemento son consustanciales al lenguaje:

La materia de este arte es el lenguaje, y ésta es, ciertamente prestada, no propia. La finalidad del mismo hablar bien; la de quien lo ejercita expresar su pensamiento, o persuadir de lo que quiere, o provocar alguna reacción anímica o calmarla. Todo lenguaje consta de palabras e ideas, algo así como de cuerpo y alma: las ideas son el alma y, por así decir, la vida de las palabras, por eso incluso se las llama indistintamente alma y sentido. Cosa vacía y muerta son las palabras desprovistas de sentido; por otra parte, las palabras son la sede de las ideas y constituyen una especie de destellos de luz en medio de la gran oscuridad que cubre nuestro espíritu (Vives, 2000:9-10). 


\section{4) El dueño y señor de la lengua}

Vives, más amante del pragmatismo que de la dialéctica, en su etapa madura en la que reflexiona y escribe sobre la lengua, no da rodeos para decir que el origen de ésta está en el pueblo. Éste es quien la va construyendo y que los cambios que ésta sufre a lo largo del tiempo es por obra y gracia de lo que hacen y dicen los hablantes de esa lengua. Vives diferencia claramente, entre el protagonista de la lengua, el pueblo, y el que se encarga de determinar y fijar lo que se habla por el pueblo, el gramático. La claridad con la que Vives expresa estas dos funciones, a veces, no suficientemente deslindadas, parece más bien pertenecer a la distinción ente gramática descriptiva (donde tiene prioridad el uso) y gramática normativa (en la que una institución prescribe el modo de usar la lengua), tal como aparece señalado en la Parte Primera (Tomo I), de su obra De Disciplinis, dedicada a examinar Las causas de la corrupción de las Artes:

Puesto que el arbitrio de la lengua está en manos del pueblo, dueño de su propio lenguaje, el lenguaje sufre cambios continuadamente, hasta el punto que aproximadamente cada cien años es ya completamente distinto, y quienes viven en un momento determinado no comprenden la lengua de aquellos que existieron cien años antes. Por tanto, a fin de no perder por completo el conocimiento de los antiguos escritores, se cuidó que hubiera profesores que atendieran el propósito de mantener la fuerza y significación de todas las palabras y ser como guardianes de ese tesoro y tribunos del erario:

'El derecho del lenguaje', como dice Horario, es 'propiedad del pueblo' (Vives, 1997:104-105-Tomo I).

\section{5) Las disciplinas que tratan y desarrollan la lengua}

Lo que no le falta a Juan Luis Vives es la visión general para someter a examen el arte de la lengua. El buen conocimiento que tenía del mundo clásico antiguo le lleva a decir que por unánime consentimiento de los escritores antiguos, la lengua ha sido tratada por tres disciplinas (artes): la gramática, la retórica y la dialéctica. Vives, buen conocedor de las tres, a nivel teórico y práctico, nos ha dejado en sus escritos muchas reflexiones sobre las mismas (Cf. Mack:2008); sin embargo será a la retórica a la que dedique especial atención en su obra ya mencionada, De ratione dicendi (Del arte de hablar).

La claridad de ideas que Vives tiene en relación a las tres disciplinas mencionadas, le lleva a expresar de modo categórico los cometidos de las mismas de la forma siguiente: 
De común acuerdo los antiguos escritores establecieron tres artes que tratan del lenguaje: la gramática que mostraba qué se decía y de qué manera; la retórica, el ornato y el lujo; la dialéctica, los argumentos y la probabilidad. En consecuencia, reside en la gramática aquello que ellos quieren enseñar, en la dialéctica lo que quieren probar, en la retórica los sentimientos que quieren mover (Vives, 1997:103-Tomo I).

A lo largo de todos los comentarios que hace Vives en su obra a propósito de la lengua, hay algo que subyace a todas sus reflexiones: el pragmatismo y la flexibilidad que le guía a la hora de identificar la realidad de la lengua, la definición de su uso y la elección de los temas que conviene tratar. Edward V. George, a propósito de comentarnos cómo el Renacimiento Italiano entendía la retórica, nos señala que Vives entendió y aplicó esta disciplina desde una perspectiva pragmática:

In the earlier Italian Renaissance tradition of bringing rethorical skill to community activity, the background was set for the objective which rethorical study was to assume in Vives: namely, eloquence in communal discourse of all kinds, which he, like many humanists, judged to be severely hampered by the corrupting influence of late scholastic dialectic. In Vives thought, it was largely to the pursuit of rethoric that the mission of overcoming this influence fell. Renaissance rethoric, as described by Monfasany exhibited two tendencies: the integralist, whose aim was 'to revive the full classical art of rethoric', and the pragmatic, which aimed to 'to adapt classical rethoric to contemporary practices and values'. By this analysis Vives' rethorical doctrine clearly falls into the second category (George, 1992:114).

El valenciano, al igual que no siguió de forma rígida la tradición antigua en el uso de las lenguas clásicas, concretamente el latín o la tradición ciceroniana, como ya se ha indicado anteriormente, lo mismo hace en relación al modo de entender la lengua en general y el cometido de los gramáticos. Vives es contrario al formulismo y puritanismo lingüístico, por ser factores generadores de vicios en el hablar y en el escribir:

Este arte resultó enriquecido e ilustrado por una diligencia adecuada, pero lo oscureció la excesiva y lo destruyó de raíz la mínima. Algunos encontraron fórmulas del arte a partir de la analogía e intentaron derivar el vastísimo río del uso hacia estas, por así decirlo, acequias, cuando a partir del uso fue observada y nació la gramática, así como la dialéctica y la retórica, no el uso a partir de ellas. Así, no sólo debilitaron y quebrantaron el lenguaje, reducido a una mísera prescripción de fórmulas, sino que lo corrompieron también con gran cantidad de vicios, hablando de manera distinta a la conveniente, según los cánones, no según la costumbre, que es la dueña y señora del lenguaje. De esta manera puedes ver a muchos preceptores de este arte muy puntillosos con horribles equivocaciones e infamias en la oración al seguir el arte, que no ha podido abarcar todo el uso debido a que éste es variado y no sigue la analogía. Así pues no fueron capaces de anotarlo todo según unas reglas. Además, cambia indiscriminadamente, 
según el arbitrio de la multitud, en cuyas manos se encuentra la lengua (Vives, 1997:105-106-Tomo I).

De la misma manera, Vives también critica a aquellos expertos en la lengua (gramáticos) que llevados de su rigidez y ceguera solo tratan las cuestiones abordadas por un solo autor, sea Cicerón u otro. Ello les impide, lógicamente, escribir de otros temas que el nuevo contexto cambiante del siglo XVI tiene planteados y que es conveniente examinar. Al respecto, es bastante ilustrador el siguiente comentario de Juan Luis Vives:

Hay quienes temen contaminarse si dicen algo en un latín diferente del de Cicerón, por un escrúpulo ridículo, por no llamarlo estúpida superstición. En primer lugar, ¿cómo podrán hablar de aquello que no está en Cicerón, de la construcción, de la zapatería, de la tejeduría, del cultivo del campo, si no es porque todo van a tomarlo de unas pocas palabras suyas en el Catón el Mayor y en algunas cartas a su hermano y a Ático? Necesario será que enmudezcan en las demás materias, para no hablar de manera poco ciceroniana, será ciertamente preferible callar que hablar mal. ¿Qué harán en la poesía, en la historia, géneros en los que él no escribió? ¿Y qué hay del hecho de que dijo ciertas cosas que con no menor agudeza, gracia y exactitud en la declaración o en la persuasión son dichas por los demás? Sin duda hay en él algunas que si se hubieran recogido más concisa y sucintamente tendrían más nervio y eficacia (Vives, 1997:108-Tomo I).

\section{3. La perspectiva didáctica de Vives en el uso de la lengua y del lenguaje}

Aparte de otras orientaciones que están presentes en el conjunto de la obra vivesiana, tal como se ha indicado anteriormente, la perspectiva didáctica (pedagógica) en Vives es una cuestión relevante en su producción científica ${ }^{8}$, sobre todo cuando aborda la cuestión de la lengua y el uso del lenguaje. Ello explica que su Linguae latinae exercitatio o Diálogos (1539) sea la obra con mayor número de ediciones y de traducciones a diversos idiomas, en la que el valenciano plantea la didáctica de las lenguas. En otros momentos Vives también se interesó por la manera en que se debe enseñar las lenguas, así como por la dialectología, por la teoría de la traducción y por la mejor forma de expresarse. De hecho, al no ocuparse de la gramática desde un punto de vista abstracto, nunca dedicó a ella exclusivamente libro alguno.

Para todos los humanistas, incluido Vives, la didáctica como concepto típicamente humanista, es un proceso de formación de hombres y por lo tanto es esencial,

\footnotetext{
8 Para ver la importancia y difusión que tuvo la perspectiva pedagógica en Vives puede consultarse el interesante artículo de Enrique González titulado "Lectura de Vives, del siglo XIX a nuestros días" (1992b:1-76).
} 
ya que permite al hombre acceder al conocimiento. En lo que respecta al conocimiento, una correcta argumentación es una parte muy importante, pues no se trata de acumular información, sino de transmitirla y de expresarla, y por lo tanto se produce la relación entre lenguaje y saberes.

La aportación de Vives a la didáctica ha sido importante, al poner la psicología al servicio de la pedagogía didáctica y al tratar sobre diferentes cuestiones básicas para toda programación didáctica (Cf. Esteban y López, 1997:50).

Vives, en efecto, no repara en señalar todo tipo de orientaciones y detalles que, a su entender, deben guiar el proceso de la enseñanza, tanto en su enfoque didáctico más general, como en las condiciones materiales que deben existir para que el aprendizaje se lleve a cabo con los mejores rendimientos. Al respecto, conviene de nuevo señalar la gran contribución que hizo Vives al universo didáctico, especialmente con su extensa obra De Disciplinis, en la que aborda cuestiones tan relevantes como las relacionadas con el arte de enseñar, tales como las necesidades del hombre en relación a las artes en general, los agentes del proceso de enseñanza (profesores y alumnos), el aprendizaje de la lengua y su metodología, etc.

Para asegurar un proceso de enseñanza adecuado, en opinión de Vives, deben existir buenas condiciones materiales y humanas; de otra forma resultará difícil conseguir los mejores resultados en el aprendizaje.

Las condiciones materiales, son para Juan Luis Vives, elementos muy básicos a tener en cuenta. Con esta reflexión el valenciano se adelanta en el tiempo a la cuestión que más tarde se planteará sobre la importancia del espacio físico escolar y su infraestructura y equipamiento para tener una buena escuela:

Considero que ante todo se debe hablar acerca del lugar, pues es lo primero que suele mirarse en la constitución de una escuela. En él conviene que se tengan en cuenta los siguientes factores. Que el aire sea saludable, para que los escolares no se vean enseguida obligados a huir, atemorizados por el miedo a alguna epidemia [...] Pero tampoco elegiría yo un lugar tan placentero y agradable que pudiera incitar a los escolares a salir frecuentemente, a no ser que deban dedicarse a deliciosas disciplinas como la poesía, la música o la historia (Vives, 1997:43-Tomo II).

Pero si las condiciones materiales son tan fundamentales para el proceso de aprendizaje, no lo son menos las condiciones humanas, es decir el factor humano. También Vives, al asignarle tanta importancia al capital humano en el proceso de enseñanza, no hizo sino adelantarse a su tiempo al poner de manifiesto el papel del maestro en el aprendizaje del alumno:

Pero quienes más hacen para el lugar son los hombres. Así pues, que no sólo sean maestros en una disciplina, para poder impartirla correctamente, sino que tengan también la 
facultad y la destreza para enseñar. Que sus costumbres sean honradas. Ésta será su primera preocupación: no hacer o decir nada a partir de lo cual se pudiera ofrecer un mal ejemplo al discípulo o algo cuya imitación no sea segura (Vives, 1997:45-Tomo II).

Juan Luis Vives considera las siguientes ideas funcionales como método de aprendizaje:

En primer lugar, dice que el aprendizaje de las lenguas clásicas debe hacerse a una edad temprana; con lo cual Vives adelanta algo que posteriormente la metodología del aprendizaje de las lenguas ha puesto de manifiesto: cuanto antes se inicie a los niños en el estudio de las lenguas, los resultados obtenidos serán mejores. En la Carta Primera que contiene la obra De Ratione Studii Puerilis y que es un breve plan de estudios que Juan Luis Vives concibe, para que lo use el preceptor de María, hija de Doña Catalina, reina de Inglaterra. En ella, el valenciano orienta sobre cómo proceder en cuanto a cuestiones que forman parte del método de aprendizaje de las lenguas y relativas a la lectura, escritura, sintaxis, autores, lenguaje, ejercicios de redacción latina, etc. Concretamente, al escribir el lenguaje, Vives afirma el interés que tiene realizar el aprendizaje del latín a edad temprana:

Hable la niña con su preceptor y con sus condiscípulos en latín [...]; esfuércese por expresar lo que leyó en los autores y hable ella a su vez como oyere que hablen los otros a quien ella tenga por instruidos, después de haberlos escuchado con toda atención. Esa imitación en los estudios es cosa no poco útil, especialmente en la edad tierna, para quien el mimetismo es lo más gustoso y mejor. Y no solamente remedará las voces, sino también la pronunciación por no cometer falta en los acentos (Vives, 1948:325-Tomo II) ${ }^{9}$.

En segundo lugar, pone de relieve la utilidad de conocer bien y apoyarse en la lengua vernácula propia para el aprendizaje de las otras lenguas. Vives defiende el uso de la lengua vernácula, ya que según él, facilita el aprendizaje de las lenguas clásicas. Con esta posición, el valenciano avanza bastante, en términos de método de aprendizaje de las lenguas, y se distancia de Erasmo quien se quedó prácticamente encerrado en el uso de la lengua latina:

En este punto comenzará a verter pequeñas oraciones del inglés al latín, fáciles al principio y de una dificultad gradual después, en que entren en juego todos los géneros y tiempos de los verbos. Estas oracioncillas deben ser graves y de sano contenido, o festivas, salpicadas de gracejo urbano y de sales áticas (Vives, 1948:323-Tomo II).

\footnotetext{
${ }^{9}$ Se ha recurrido a la traducción que hace Riber de la obra de Vives De Ratione Studii Puerilis, contenida en la Carta que Vives escribe a Catalina, reina de Inglaterra (1523), al no disponer de otra traducción en castellano de dicha obra. La edición en castellano del Epistolario de Juan Luis Vives y preparada por Jiménez Delgado no incluye todo el texto de dicha carta, remitiendo a tal fin a las ediciones de las obras de Vives preparadas por Mayans (Valencia 1782-1790 y Londres 1964) y Riber (1948) [Vives: 1978:324-325].
} 
En tercer lugar, otra idea que está en su concepción de la didáctica es que para mejorar el aprendizaje conviene seguir el ejemplo de los que hablan y escriben bien. Vives, lejos de ser un formalista y un purista en el uso de la lengua, sí cree necesario como método de enseñanza imitar a los que bien hablan y escriben. Esta idea está fuera de duda y se ha constituido en un principio de aprendizaje fundamental en cualquier propuesta metodológica:

Habla tú como oyeres que hablan los hombres doctos o leyeres en los escritores latinos. Evita, así en el hablar como en el escribir, todas aquellas voces que te parecieren sospechosas sin haberte previamente informado de tu maestro acerca de su latinidad. Con aquellos que hablan el latín incorrectamente, puesto que su locución puede corromper la tuya, prefiere hablar en inglés o en cualquier otra lengua en la que no exista tal peligro. Gusta de alternar con los que tienen una templada facundia. No hay deleite más puro ni subido que el de hablar con quienes tienen en su lengua remedios obvios y eficaces para todas las dolencias del alma (Vives, 1948:329-330-Tomo II).

En cuarto lugar, Vives también defiende que la enseñanza de las lenguas clásicas, concretamente el latín, debe hacerse por un maestro que conozca perfectamente su propia lengua vernácula. De nuevo, Vives sitúa a la lengua vulgar como instrumento de apoyo para el aprendizaje de lenguas no propias. Resulta difícil entender otra situación que no sea la indicada, para que tenga lugar un aprendizaje en las adecuadas condiciones. No es fácil encontrar otro texto de Vives al respecto, en el que exponga con tanta claridad la cualificación que debe tener el maestro de su propia lengua vernácula:

De la lengua vernácula de los niños tendrá el maestro un conocimiento exacto para enseñarles a través de ésta de manera más cómoda y sencilla aquellas lenguas eruditas, pues, si en la lengua patria no usa de vocablos convenientes y adecuados al tema del que se habla, a menudo llevará a engaño a los niños y este error les acompañará tenazmente cuando sean ya adultos y grandes. ¿Qué decir del hecho de que los niños no entienden bien ni su propia lengua, a no ser que se diga todo con claridad meridiana? Conserve íntegra la memoria de la lengua patria en toda su antigüedad y tenga conocimiento no sólo de las palabras recientes, sino también de las arcaicas y que quedaron ya obsoletas, y sea como una especie de administrador del erario de su lengua (Vives, 1997:87-Tomo II).

En quinto lugar, Vives igualmente piensa que la utilización de la lengua vernácula en la enseñanza facilita una explicación clara y accesible y considera buen método de enseñanza ir de lo fácil a lo difícil, de lo simple a lo complejo, de lo accesible a lo que presenta más dificultad. Y en esta transición el uso de la lengua vernácula facilita el camino del aprendizaje: 
Sea la explicación del preceptor en extremo fácil y diáfana. Al principio, hágase en palabras de la lengua vulgar, luego, paulatinamente, en voces latinas con una pronunciación clara y gestos que ayuden a la comprensión, siempre que no degeneren en el histrionismo (Vives, 1997:88-Tomo II).

En sexto y último lugar, conviene destacar la idea vivesiana de que la práctica es un elemento necesario para el aprendizaje de las lenguas. De nuevo el sentido pragmático de Vives aparece en esta idea, ya que es consciente de que no importa en qué enseñanza, ésta debe tener al mismo tiempo una orientación teórica y práctica. Vives todavía recordaba su experiencia en París cursando los estudios de filosofía. Allí pudo comprobar los excesos que se producían en la enseñanza de la dialéctica, bastante orientada a la pura especulación y alejada de planteamientos reales:

La práctica de la escritura es provechosa en gran manera. Cicerón dice: 'La pluma es el mejor maestro y perfeccionador del lenguaje’. Por lo tanto, después de que hayan aprendido la sintaxis, traducirán oraciones de la lengua vulgar a la latina y, asimismo, de ésta a la lengua vulgar, pero serán al principio muy breves y se les irá añadiendo cada día algún elemento. Se obrará de idéntica manera en la lengua griega, aunque yo preferiría que aprendieran a verter de los griegos a nosotros que de nosotros a aquéllos (Vives, 1997:96-Tomo II).

Concluyendo se puede decir que Vives aplica la didáctica a la enseñanza de la lengua y del lenguaje. Para él, las lenguas se deben aprender a través de la comunicación directa y la enseñanza en general debería basarse en la experiencia y en el contacto con los hombres. No obstante, en el caso del latín, teniendo en cuenta que dicha lengua no se habla de modo natural fuera del aula, Vives se ve obligado a incluir reglas gramaticales en su método didáctico para que se estudien al mismo tiempo que se aprende a conversar, aunque lo fundamental de dichas reglas es que se apliquen en la comunicación diaria.

Después del examen de las aportaciones de Vives a la lengua y al lenguaje, se puede decir que fue un visionario de la didáctica de las lenguas y, a su vez, aplicó todos los elementos positivos de la época en la que escribió.

\section{4. Juan Luis Vives y el campo de la filología}

Vives con sus escritos filológicos realiza una amplia obra filológica y muestra un especial interés por las cuestiones relativas a este campo ${ }^{10}$. En ella, aparte de

10 Jozef IJsewijn al respecto "[...] concluded that philological problems were dear to his heart. Moreover, if we take a look also at his major works De causis corruptarum artium [...], we will soon 
abordar cuestiones de considerable interés, también describe quiénes son los filólogos, de qué se ocupan, la capacidad de que pueden estar dotados y el cometido fundamental que deben llevar a cabo. Este último aspecto me interesa especialmente subrayarlo, tanto por mi condición de filólogo como por la contribución de Vives a delimitar el oficio de filólogo en un tiempo en el que primaba más la razón epistemológica que la razón puramente profesional, como sucede actualmente:

\begin{abstract}
Hay en estas dos lenguas algunos escritores mixtos que tratan al tiempo de sucesos históricos, de fábulas, de significados de voces, de oratoria y de filosofía, cuyo nombre verdadero y más propio es el de filólogos [...] Quien más sano de ingenio y juicio no quiera, sin embargo, o no pueda adecuadamente ascender más alto, se contentará con el conocimiento de las lenguas y autores. Además, este saber le servirá en la vida para ser escriba público de la ciudad, desempeñar magistraturas menores o ejercer de embajador. Tendrán éstos y aquellos más arriba mencionados pericia en ambas lenguas, con la que aliviar el pesado tedio de la senectud mediante la lectura de los autores [...] Estos son los filólogos y su profesión la filología.

De ellos serán escogidos algunos que instruyan a los otros. No queremos que estos elegidos se limiten a lo que hemos descrito, sino que también escruten y con profundidad conozcan todo lo demás que atañe a la filología (Vives, 1997:131, 134-Tomo II).
\end{abstract}

El lógico interés que tenía Vives por las lenguas, de las que hablaba varias, le condujo no sólo a señalar el método para su enseñanza sino que también hizo un considerable esfuerzo filológico haciendo lecturas e introducciones de varios textos clásicos latinos y también griegos, y transmitiendo su opinión acerca de la forma de realizar versiones o interpretaciones, como él llama. Su trabajo filológico adquirió tal perspectiva que, como señala León Esteban, elevará la Filología a la categoría de la Filosofía, en su intento por la elaboración lingüística del pensamiento (Cf. Esteban, 1997:17).

En cuanto a sus escritos filológicos, conviene decir que éstos son abundantes y la mayoría de ellos corresponden a la primera etapa de su producción científica. Por solo citar algunos de estos escritos, cabe mencionar: Pompeius fugens (La fuga de Pompeyo, 1519); In Somnium Scipionis (Sueño al margen del «Sueño de Escipión», 1519); Declamationes Sillanae (Declamaciones Silanas, 1520); Oración Areopagítica. Nicocles. Discursos de Isócrates (1523), traducidos por el propio Vives del griego al latín; Interpretatio Allegorica in Bucolica Virgilii (Interpretación Alegórica de las Bucólicas de Virgilio, 1537).

En todos sus escritos filológicos Vives puso de manifiesto el dominio que tenía de la lengua y de la cultura latina, pero también de la griega. No cabe duda que la elección de los escritos en cuestión respondían a los intereses que Vives tenía por los contenidos temáticos a los que el valenciano pretendía dar actualidad.

find that Vives has devoted some very thorough and most relevant considerations on the philological problems and that he easily ranks among the serious theoreticians of this of many other arts" (1992:79). 


\section{Juan Luis Vives y el arte de traducir e interpretar}

Como cuestión general, es importante decir -recordando el pensamiento de Gadamer- que el lenguaje de la traducción debe servir para divulgar una obra, estrechándose el vínculo entre lector y escritor original:

[...] Por eso la tarea de la traducción goza siempre de una cierta «libertad». Presupone la plena comprensión de la lengua extranjera, pero aún más la comprensión del sentido auténtico de lo manifestado. El que quiera hacerse entender como intérprete debe traducir el sentido expresado. La labor de la «hermeneútica» es siempre esa transferencia desde un mundo a otro, desde el mundo de los dioses al de los humanos, desde el mundo de una lengua extraña al mundo de la lengua propia (los traductores humanos sólo pueden traducir a su propia lengua (Gadamer, 2006:95- II).

La concepción de Juan Luis Vives sobre el arte de la traducción y de la interpretación nos lleva a considerar dos aspectos que permiten hacer una valoración de la misma: por un lado, las contribuciones anteriores en materia de traducción e interpretación y, por otro, las aportaciones específicas de Juan Luis Vives a dicho campo.

\section{1) Contribuciones anteriores en materia de traducción e interpretación}

Juan Luis Vives conoce muy bien y, además, las tiene en cuenta, las dos tradiciones anteriores y más significativas que en torno a la traducción se produjeron, y que se derivaron del trabajo de versión de obras clásicas escritas en griego al latín. Ambas tradiciones están representadas fundamentalmente por Cicerón y San Jerónimo.

Cicerón, por su parte, representando la tradición del clasicismo latino (Cf. Calvo, 1984:70-71) se implica directamente en el oficio de traductor, vertiendo el Protágoras de Platón, el Oeconomicon de Jenofonte y un Discurso de Esquines y Demóstenes. Pero, aún más, en su obra De Optimo Genere Oratorum, Cicerón desprecia la traducción literal y el seguimiento pedestre del texto literal. El clásico latino entiende la traducción como un ejercicio de elocuencia, lo que le lleva a identificar lo esencial del texto original para posteriormente recrearlo en el idioma propio. Por tanto, la filosofía que orienta la labor traductora en Cicerón es la de trabajar la versión con sentido libre, nada de esclavitud ante el texto original. Por ello, Cicerón muestra la idea humanista de que no hay que ceñirse estrictamente a ningún modelo.

San Jerónimo, por otra parte, representando la tradición cristiana (Cf. Calvo, 1984:71-72) y autor de la versión Vulgata de la Biblia, se constituye en un referen- 
te teórico principal en el campo de la traducción a lo largo de toda la Edad Media y su influencia llega hasta la época moderna. La aportación de San Jerónimo va más allá de la de Cicerón, ya que especifica el sentido de la traducción para todo tipo de textos y diferencia el sentido de la traducción según de qué texto se trate. De aquí que el Santo distinga dos tipos de traducción: traducción libre para los textos profanos, al igual que Cicerón que lo hace con carácter general, y traducción literal para los textos sagrados, no confundiendo ésta con cualquier traducción pedestre o esclava de la letra. Ello, en su opinión, obligará al traductor a conocer muy bien la propia lengua para poder hacer la versión en las mejores condiciones:

Para ello, el traductor deberá partir de un intensivo conocimiento de la propia lengua para poder, con los medios de que dispone, confiarse a la lengua del original en la medida en que Dios le dé conocimiento y fuerzas. Y si la lengua propia no le permite transfigurar todo el contenido del original, deberá tener el valor de expresar esa «proprietas peregrini sermonis» por medio de la lingüística personal. Para estos casos concretos vuelve a apoyarse en Cicerón, específicamente en su De oratore (Calvo, 1984:71).

\section{2) Aportaciones específicas de Juan Luis Vives al campo de la traducción e interpretación}

Vives tiene en cuenta y le interesan las dos grandes corrientes teóricas de la traducción mencionadas, entre otras razones porque éstas se han generado a partir de la versión de textos escritos en lenguas clásicas, de lo mismo que el valenciano se ocupa.

De todas formas, seguro que también Vives conoce otras aportaciones al campo de la traducción que se han producido desde la Baja Edad Media hasta los primeros años del Renacimiento por la vía de la traducción de textos sagrados al romance o por la versión de textos clásicos, principalmente del griego a la lengua latina. Entre las contribuciones más significativas de este periodo, cercano a Juan Luis Vives, tenemos las que representan eruditos de la traducción como el griego Chrysoloras (1355-1415), el italiano Guarino de Verona (1370-1460)11 y el también italiano Leonardo Bruni (1370-1444), quien al traducir textos de Platón, Jenofonte, Plutarco y Aristóteles lo hace con una bella factura, siguiendo las tradiciones de Cicerón y Petrarca y proclamando que una buena traducción debe hacerse bajo aquellos requerimientos que aseguren la calidad de la misma:

11 Según Guarino, la traducción era importante pues ayudaba a recordar las frases que se vertían de una lengua a otra. En sus clases, la traducción iba acompañada de la pronunciación y un breve comentario (Cf. Breva-Claramonte, 1994:29). 
Conocimiento perfecto de ambas lenguas (premisa ésta muy teórica todavía en sus antecesores), amplios conocimientos culturales, una elevada erudición y la concordancia estilística con el autor que se traslada. Esta última premisa, que lo emparenta como ya hemos visto con San Jerónimo, la expresa Bruni destacando brevemente lo que él considera esencial en cada uno de los autores: «amplitudo et copia» en Cicerón, «exilitas et brevitas» en Salustio, «granditas quaedam subaspera» en Tito Livio. Adecuación estilística si bien en grandes rasgos. Bruni destacará la empatía que aún hoy resulta conveniente para la mejor recreación del original (Calvo, 1984:73).

¿Cómo entiende, pues, Vives la traducción?

En términos generales, Vives entiende la traducción como el ejercicio de versión de las palabras de una lengua a otra, pero manteniendo y conservando el sentido del texto original (Cf. Vives, 2000:169-174). Es importante, sigue pensando el valenciano, que cuando utilicemos el lenguaje para divulgar una obra a través de la traducción, el autor de la traducción, estreche a través del lenguaje el vínculo entre escritor original y lector y que éste perciba la actualidad del tema (Cf. Vives, 2000:169-174).

Pero a partir de aquí, y en esto va a consistir su aportación específica, incorpora la contribución de carácter textual que al respecto hizo San Jerónimo, pero yendo más lejos o ampliando dicho carácter; es decir, tiene en cuenta como cuestión previa el tipo de texto de que se trata y a partir de aquí procede a la traducción. Vives, a diferencia de la distinción jeronimiana entre textos profanos (traducción libre) y sagrados (traducción fiel), distingue tres tipos de textos a los que corresponden también tres tipos distintos de traducción:

En algunas de ellas (palabras) tan sólo se atiende al sentido, en otras sólo al estilo de la expresión, por ejemplo, si se intenta trasladar a otras lenguas los discursos de Demóstenes o de Marco Tulio, o la poesía de Homero o de Marón, conservando en todo su ser la apariencia y el color de su lenguaje [...] El tercer tipo se da cuando tanto al contenido como a las palabras se les otorga la misma importancia, es decir, cuando las palabras aportan fuerza y encanto al sentido, y ello tanto si se las considera de forma aislada, en unión o en todo el conjunto del discurso (Vives, 2000:169).

Por tanto, teniendo en cuenta el texto anterior de Vives, podemos expresar de la siguiente manera la relación que éste establece entre tipos de texto y traducción:

El primer tipo de texto sería aquel que antepone el qué: la esencia, al cómo: la forma. En este caso, lo importante es conservar el sentido y, por tanto, se puede traducir con cierta libertad, añadiendo las palabras o expresiones que puedan ayudar a comprender lo que se dice en el original. Parece que Vives está pensando en textos de carácter informativo (Cf. Calvo, 1984:74).

En el segundo tipo de texto, lo que prevalece es la forma, el cómo. Para este caso, la traducción debe ser principalmente formal, atendiendo al cómo se dice, $\mathrm{y}$ 
afectaría básicamente a los textos sagrados, concretamente, a la Sagrada Escritura.

En el tercer tipo de texto, Vives conjuga los dos tipos de texto anteriores, es decir, el sentido y la forma, y a tal fin se deberá combinar, a la vez, la conservación del contenido y de aquellas expresiones y formas idiomáticas de la lengua original en la lengua traducida, salvo cuando la traslación literal no sea posible y haya que traducir por equivalencia. Este tercer método de traducción que Vives propone, exige un equilibrio entre el sentido y la forma, y plantea más dificultades y esfuerzo para el traductor. Parece ser que Vives está pensando en este tercer tipo de texto en textos literarios, tal como indica Calvo:

También aquí, aunque sin expresarlo claramente, creemos que Vives se está refiriendo a la traducción de textos literarios que exigirían por lo menos una analogía con el original. La imposibilidad de llegar a este compromiso parece clara para el humanista (cada escritor es una persona diferente), otorgando con ello una mayor libertad a la traducción poética en lo que a la forma se refiere, pero exigiendo, a su vez, que se guarde la mayor fidelidad posible a los contenidos semánticos de la «sententiae summa» (Calvo, 1984:74).

Aparte la aportación de Vives en relación a la tipología textual, también hay otras cuestiones que le preocupan al valenciano en el oficio de la traducción:

La cualificación del traductor en las lenguas que traduce y en la materia objeto de traducción. Si éste no está versado en ambos campos, difícilmente se pueden esperar buenos resultados, tal como nos lo recuerda en el siguiente pasaje:

Para traducir bien es necesario que el intérprete sea muy buen conocedor de ambas lenguas, aun cuando conviene que esté más versado en aquella a la cual vierte. No pueden, empero, traducirse sin mengua aquellos vocablos cuyo sentido se ignora del todo. Poco adecuado será el modo en que interprete las obras de Aristóteles, quien no sea filósofo, y no interpretará como es debido las de Galeno, quien no sea médico (Vives, 1997:9697-Tomo II).

Dar importancia a las traducciones. Vives pone de manifiesto el interés que tiene para todas las disciplinas utilizar el instrumento de la traducción, lógicamente si éste se usa bien:

Las traducciones son no sólo útiles, sino también extremadamente necesarias tanto para todas las disciplinas y artes como, en particular, para casi todas las circunstancias de la vida, siempre y cuando sean fieles. Se tornan falsas bien por la ignorancia de las lenguas, bien por la de la materia de la que se trata (Vives, 2000:170).

La calidad de la versión realizada. Vives exige perfección, exactitud y calidad en el trabajo de traducción y es bastante crítico con las versiones mal hechas: 
Cuanto más fielmente hayas conservado el encanto del discurso y cuanto más propiamente lo hayas interpretado al pie de la letra, tanto mejor y más notable será la traducción, es decir, reproducirá más verazmente su original; es lo que ocurre con la obrita de Cicerón De universitate, parte del Timeo de Platón, que yo propondría a los estudiosos como un inmejorable original para traducir (Vives, 2000:173).

En resumen, Juan Luis Vives también en el campo de la traducción e interpretación es capaz, dado su interés por el lenguaje, de contribuir a la tradición traductológica que recibe, y que aplica teniendo en cuenta la tipología textual (Cf. Calero:1990), y sabe situarse en lo que será el futuro de este campo, gracias a la concepción moderna que del humanismo tiene y al rigor científico con el que trabaja:

Si bien Vives parte en líneas generales de la concepción ciceroniana/jeronimiana hasta aquel momento tradicional y vigente, supera a ambos en su relatividad del hecho traductor como supeditado a la tipología textual, adoptando, no una «forma» abstracta y universalmente válida para toda traducción que no sean las Sagradas Escrituras, sino toda una serie de posibilidades de traducción, un abanico esencialmente trilítero, que nos llegará a nuestros días y que planteará con siglos de antelación, no solo las principales premisas textuales del Romanticismo, sino la misma traductología germánica de base textual que se está dando en esta segunda mitad del siglo XX (Calvo, 1984:74-75).

\section{A modo de conclusión general}

De las reflexiones que hemos hecho en las páginas anteriores sobre el pensamiento de Vives en relación a la lengua, el lenguaje y la traducción, queremos concluir señalando algunas de ellas que nos parecen más sugerentes al respecto:

Lengua y lenguaje son dos conceptos que adquieren verdadera fuerza en Vives cuando son vistos desde la perspectiva de su obra filosófica, concretamente en su escrito De Disciplinis.

El conocimiento de las lenguas, en opinión de Vives, es algo que no se agota en sí mismo, sino que son un medio que nos sitúan a las puertas de las artes, de las disciplinas y de los saberes.

Vives no es solo un usuario de las lenguas, sino que reflexiona acerca de la lengua en general y propone metodologías para su aprendizaje.

Vives hace un reconocimiento de la lengua vernácula, aunque siempre toma las cautelas necesarias para que prevalezca la hegemonía del latín y del griego sobre ésta.

Por la perspectiva que adquiere el trabajo filológico de Vives, éste elevará la Filología a la categoría de la Filosofía, en su intento por la elaboración lingüística del pensamiento. 
En el campo de la traducción e interpretación, Vives contribuye a la tradición traductológica que recibe y la aplica teniendo en cuenta la tipología textual.

\section{Bibliografía}

Breva-Claramonte, M. (1994), La didáctica de las lenguas en el Renacimiento. Bilbao, Universidad de Deusto.

Calero, F. (1990), «Sobre la teoría de la traducción de Luis Vives», en VV.AA., Homenaje a J. Esteve Forriol. Valencia, Universidad de Valencia, pp. 39-46.

Calero, F. (1996), “'Traiciones' a Luis Vives», en Anales del Seminario de Historia de la Filosofia, $\mathrm{n}^{\circ} 13$, pp. 237-245.

Calero, F. (1998), «Traducir a Vives», en Cuad. Filol. Clás. Estudios Latinos, $\mathrm{n}^{\circ} 15$, pp. 529-539.

CALERO, F. (2009), «La lengua vernácula y Luis Vives: a propósito de la autoría del Diálogo de la Lengua», en Espéculo. Revista de Estudios Literarios, nº 41.

CALvo, J. J. (1984), «Juan Luis Vives: ¿Un pionero de la traductología moderna? Apuntes sobre una discrepancia», en Quaderns de Filología: Miscelànea Sanchis Guarner. Universitat de Valencia, Vol. 2, pp. 69-78.

CARrera, A. (1988), El problema de la lengua en el Humanismo renacentista español. Universidad de Valladolid, Secretariado de Publicaciones.

Durán, M. A. (2000), Si Aristóteles levantara la cabeza. Madrid, Ediciones Cátedra.

Esteban, L., Editor (1997), Cuatro estudios a una obra o el "Arte de Enseñar"de Juan Luis Vives. Valencia, Ayuntament de Valencia.

Fantazzi, CH. (1979), Juan Luis Vives. In Pseudodialecticos. A critical edition. Leiden, Brill.

Fishman, J. (1979), Sociología del lenguaje. Madrid, Ediciones Cátedra.

Fontán, A. (1977), «El latín de Luis Vives», en P. Sainz Rodríguez et al., Homenaje a Luis Vives. Madrid, Fundación Universitaria Española, pp. 33-62.

Fontán, A. (1992), Juan Luis Vives (1492-1540). Humanista. Filósofo. Político. Valencia, Ajuntament de València.

Fontán, A. (2008), Príncipes y humanistas. Nebrija, Erasmo, Maquiavelo, Moro, Vives. Madrid, Marcial Pons.

Gadamer, H-G. (2006), Verdad y Método II. Salamanca, Ediciones Sígueme.

George, E.V. (1992), «Rethoric in Vives», en Ioannis Lodovici Vivis, Opera Omnia, I, Volumen Introductorio (Coordinación Antonio Mestre). Valencia, Edicions Alfons el Magnànim. Generàlitat Valenciana, pp. 113-177.

Gómez-HortigüEla, A. (1993), «Fundamentos filosóficos del humanismo de Vives», en M. Mourelle De Lema, Juan Luis Vives. Madrid, Grugalma, pp. 8596. 
GonzÁlez, E. (1992a), «Vives. De la edición Príncipe hacia el texto crítico», en Vives. Edicions Princeps. Valencia, Universitat de Valencia, pp. 13-57.

GonZÁLEZ, E. (1992b), «La lectura de Vives, del siglo XIX a nuestros días», en Ioannis Lodovici Vivis, Opera Omnia, I, Volumen Introductorio (Coordinación Antonio Mestre). Valencia, Edicions Alfons el Magnànim. Generàlitat Valenciana, pp. 1-76.

Hidalgo-SERnA, E. (1983), «Ingenium and Rethoric in the work of Vives», en Philosophy and Rethoric, Volumen 16, nº, pp. 228-241.

Hidalgo-Serna, E. (1990), «Metaphorical language, Rhetoric, and Comprehensio:

J.L. Vives and M. Nizolio», en Philosophy and Rethoric, Volumen 23, $\mathrm{n}^{\circ} 1$, pp. $1-11$.

Hidalgo-Serna, E. (1992), «Vives, Calderón y Vico. Lenguaje metafórico y filosofar ingenioso», en Cuadernos sobre Vico, n², pp. 75-88.

HidAlgo-SERnA, E. (1998), Estudio introductorio. La elocuencia y el arte retórica de Vives, en Juan Luis Vives, El arte retórica. De ratione dicendi. Barcelona, Anthropos Editorial, pp. VII-XLII.

IJSEWIJN, J. (1992), «Vives and humanistic philology», en Ioannis Lodovici Vivis, Opera Omnia, I, Volumen Introductorio (Coordinación Antonio Mestre). Valencia, Edicions Alfons el Magnànim. Generàlitat Valenciana, pp. 77-111.

JIMÉNEZ, J. (1978), «Introducción», en Juan Luis Vives, Epistolario. Madrid, Editora Nacional, pp. 9-100.

KRIPPENDORFF, K. (1997), Metodología de análisis de contenido. Barcelona, Ediciones Paidós.

Mack, P. (2008), Vives's Contributions to Rethoric and Dialectic, en Ch. Fantazzi (Ed.), A Companion to Juan Luis Vives, Leiden, Brill, pp. 227-276.

Marcos, F. (1990), El comentario lingüístico. Metodología y práctica. Madrid, Ediciones Cátedra.

Moreno, V. (2006), La recepción hispana de Luis Vives. Valencia, Conselleria de Cultura, Educaciò i Esport.

Mourelle de Lema, M. (1993), «Las ideas lingüísticas de Juan Luis Vives», en M. Mourelle De Lema, Juan Luis Vives. Madrid, Grugalma, pp. 207-226.

Nero, V. del. (1991), Linguaggio e filosofia in Vives. Bolonia. Cooperativa Libraria Universitaria.

Nero, V. del. (2008), «The De Disciplinis as a Model of a Humanistic Text», en CH. Fantazzi (Ed.), A Companion to Juan Luis Vives, Leiden, Brill, 177-226.

Nubiola, J. (1993), «Juan Luis Vives y Charles S. Pierce», en Anuario Filosófico, 26, pp. 155-164.

NúÑEZ, J. M. (1993), El ciceronianismo en España. Valladolid, Universidad de Valladolid.

Ortega y Gasset, J. (1961), Vives-Goethe. Madrid, Revista de Occidente. 
PARIS, C. (1962), «Vives y la formación del saber moderno», en Anales de la Cátedra Francisco Suarez, no 2, Fasc. 2. Universidad de Granada, pp. 235-264. RiBER, L. (1947), «Ensayo bio-bibliográfico: Juan Luis Vives, valenciano», en Juan Luis Vives, Obras Completas. Tomo I. Madrid, Editorial Aguilar, pp. 13-255.

Rodríguez, J. M. (2000), «Introducción», en Juan Luis Vives, Del arte de hablar. Granada, Editorial Universidad de Granada, pp. XIII-CXLVI.

VILlacañas, J. L. (2008), ¿Qué imperio? Córdoba, Editorial Almuzara.

VIVES, J. L. (1948), «Contra los Seudodialécticos», en Obras Completas por Lorenzo Riber (traslación, comentarios, notas y ensayo bibliográfico). Tomo II. Madrid, Editorial Aguilar.

VIVES, J. L. (1978), Epistolario. Edición preparada por José Jiménez Delgado. Madrid, Editora Nacional.

VIVES, J. L. (1997), De Disciplinis. Tomos I y II. Valencia, Ayuntament deValencia. VIVES, J. L. (2000), Del arte de hablar. Granada, Editorial Universidad de Granada. Waswo, R. (1980), «Reactions of Vives to Walla' Philosophy of language», en Bibliothèque d' Humanisme et Renaissance, $\mathrm{n}^{\circ}$ 42, pp. 595-609.

Waswo, R. (1987), Language and meaning in the Renaissance. Princeton, Princeton University Press.

Juan Luis Monreal Pérez

Departamento de Filosofía

Facultad de Filosofía

Universidad de Murcia

jlmonreal@um.es 